\title{
On the case
}

\section{Didgeridoo playing as alternative treatment for obstructive sleep apnoea syndrome: randomised controlled trial}

\author{
Milo A Puhan, Alex Suarez, Christian Lo Cascio, Alfred Zahn, Markus Heitz, Otto Braendli
}

\begin{abstract}
Objective To assess the effects of didgeridoo playing on daytime sleepiness and other outcomes related to sleep by reducing collapsibility of the upper airways in patients with moderate obstructive sleep apnoea syndrome and snoring. Design Randomised controlled trial.

Setting Private practice of a didgeridoo instructor and a single centre for sleep medicine.

Participants 25 patients aged $>18$ years with an

apnoea-hypopnoea index between 15 and 30 and who complained about snoring.

Interventions Didgeridoo lessons and daily practice at home with standardised instruments for four months. Participants in the control group remained on the waiting list for lessons.

Main outcome measure Daytime sleepiness (Epworth scale from 0 (no daytime sleepiness) to 24), sleep quality (Pittsburgh quality of sleep index from 0 (excellent sleep quality) to 21), partner rating of sleep disturbance (visual analogue scale from 0 (not disturbed) to 10), apnoea-hypopnoea index, and health related quality of life (SF-36).

Results Participants in the didgeridoo group practised an average of 5.9 days a week (SD 0.86) for 25.3 minutes (SD 3.4). Compared with the control group in the didgeridoo group daytime sleepiness (difference $-3.0,95 \%$ confidence interval -5.7 to $-0.3, \mathrm{P}=0.03$ ) and apnoea-hypopnoea index (difference $-6.2,-12.3$ to $-0.1, \mathrm{P}=0.05$ ) improved significantly and partners reported less sleep disturbance (difference $-2.8,-4.7$ to $-0.9, \mathrm{P}<0.01$ ). There was no effect on the quality of sleep (difference $-0.7,-2.1$ to $0.6, \mathrm{P}=0.27$ ). The combined analysis of sleep related outcomes showed a moderate to large effect of didgeridoo playing (difference between summary z scores -0.78 SD units, -1.27 to -0.28 , $\mathrm{P}<0.01)$. Changes in health related quality of life did not differ between groups.

Conclusion Regular didgeridoo playing is an effective treatment alternative well accepted by patients with moderate obstructive sleep apnoea syndrome.

Trial registration ISRCTN: 31571714.
\end{abstract}

\section{Introduction}

Snoring and obstructive sleep apnoea syndrome are two highly prevalent sleep disorders caused by collapse of the upper airways. ${ }^{1{ }^{3}}$ The most effective intervention for these disorders is continuous positive airway pressure therapy, which reduces daytime sleepiness ${ }^{4}$ and the risk of cardiovascular morbidity and mortality in the most severely affected patients (apnoeahypopnoea index (measured as episodes per hour) $>30) .{ }^{5}$ For moderately affected patients (apnoea-hypopnoea index 15-30) who complain about snoring and daytime sleepiness, however, continuous positive airway pressure therapy may not be suitable and other effective interventions are needed. ${ }^{167}$

AS, a didgeridoo instructor, reported that he and some of his students experienced reduced daytime sleepiness and snoring after practising with this instrument for several months. In one person, the apnoea-hypopnoea index decreased from 17 to 2 . This might be due to training of the muscles of the upper airways, which control airway dilation and wall stiffening. ${ }^{89}{ }^{10} \mathrm{We}$ tested the hypothesis that training of the upper airways by didgeridoo playing reduces daytime sleepiness in moderately affected patients.

\section{Methods}

Participants and methods

We included German speaking participants aged $>18$ years with self reported snoring and an apnoea-hypopnoea index of 15-30 (determined by a specialist in sleep medicine within the past year). Exclusion criteria were current continuous positive airway pressure therapy, use of drugs that act on the central nervous system (such as benzodiazepines), current or planned intervention for weight reduction, consumption of $\geq 14$ alcoholic drinks a week or $\geq 2$ a day, and obesity (body mass index $\geq 30 \mathrm{~kg} / \mathrm{m}^{2}$ ).

We recruited patients at our study centre (Zuercher Hoehenklinik Wald, Wald, Switzerland) and one private practice in Zurich. Physicians at the study centre assessed all potential participants for eligibility. Those willing to participate provided written informed consent. After study enrolment, all patients completed a baseline assessment.

We randomised enrolled patients into an intervention group with didgeridoo training or a control group. We used STATA software (STATA 8.2, College Station, Tx) to generate the randomisation list (ralloc command) with stratification for disease severity (apnoea-hypopnoea index 15-21 or 22-30 and Epworth score $<12$ or $\geq 12$ ). The randomisation list was concealed from the recruiting physicians and the didgeridoo instructor in an administrative office otherwise not involved in the study. We used a central telephone service, which the didgeridoo instructor used to obtain group allocation.

\section{Intervention and control}

Participants in the intervention group started their didgeridoo training after the instructor received group allocation. The instructor (AS) gave the first individual lesson immediately after randomisation. In the first lesson, participants learnt the lip technique to produce and hold the keynote for 20-30 seconds. In the second lesson (week 2) the instructor explained the concept and 


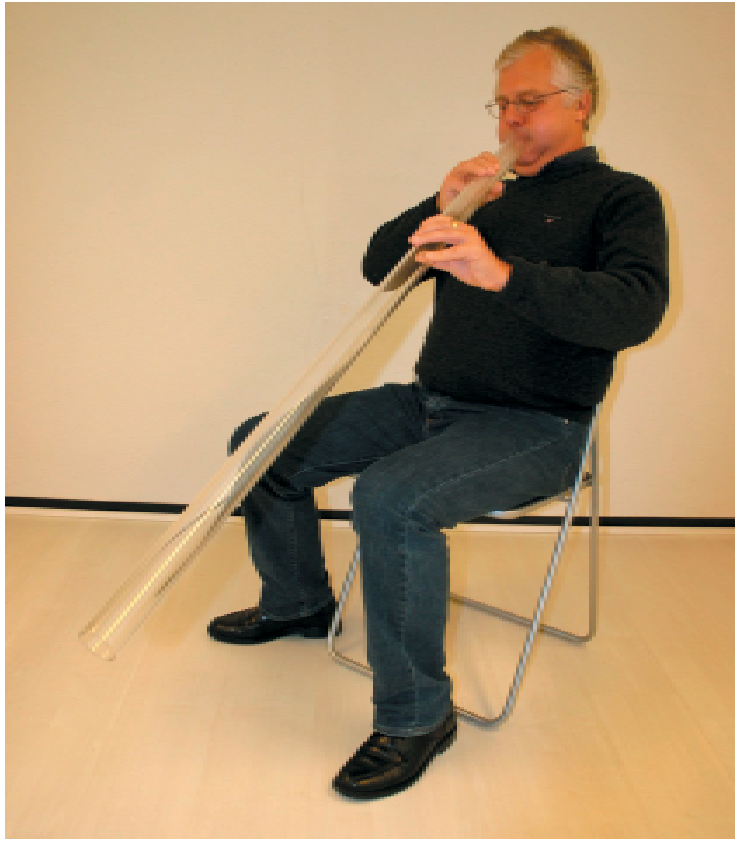

Fig 1 Man playing didgeridoo

technique of circular breathing. Circular breathing is a technique that enables the wind instrumentalist to maintain a sound for long periods of time by inhaling through the nose while maintaining airflow through the instrument, using the cheeks as bellows. In the third lesson (week 4) the didgeridoo instructor taught the participants his technique to further optimise the complex interaction between the lips, the vocal tract, and circular breathing so that the vibrations in the upper airway are more readily transmitted to the lower airways. ${ }^{11}$ In the fourth lesson, eight weeks after randomisation, the instructor and the participants repeated the basics of didgeridoo playing and made corrections when necessary. Participants had to practise at home for at least 20 minutes on at least five days a week and recorded the days with practice and the practice time (answer options for 0,20 , or 30 minutes).

Participants received a standardised acrylic plastic didgeridoo that was developed by the instructor in collaboration with Creacryl GmbH (Ebmatingen, Zurich, Switzerland, and costs $€ 80$ (£43; \$94), fig 1). The didgeridoo is $130 \mathrm{~cm}$ long with a diameter of $4 \mathrm{~cm}$ and an elliptical embouchure with a diameter of 2.8-3.2 $\mathrm{mm}$. Acrylic didgeridoos are easier for beginners to learn on than conventional wooden didgeridoos.

Participants in the control group remained on a waiting list to start their didgeridoo training after four months. They were not allowed to start didgeridoo playing during these four months.

\section{Outcome measures}

Our primary outcome was daytime sleepiness as measured by the Epworth scale, which has been validated in German speaking patients. ${ }^{12}$ Scores range from 0 (no daytime sleepiness) to 24 , and scores $>11$ represent excessive daytime sleepiness.

Secondary outcomes included three additional sleep related outcomes measures: the apnoea-hypopnoea index, the Pittsburgh quality of sleep index, and a partner's rating for sleep disturbance.

The cardiorespiratory sleep study was performed at the sleep laboratory of the study centre with a computerised system (SleepLab Pro, Jaeger, Hoechberg, Germany), according to the guidelines of the German Society for Sleep Medicine. ${ }^{13}$ We measured airflow using nasal and oral thermistors and a nasal canula with a differential pressure flow sensor. We defined episodes of apnoea as cessation of airflow of $>10$ seconds with decrements of blood oxygen saturation of $\geq 4 \%$. Hypopnoea was defined as a reduced airflow for at least 10 seconds with decrements of blood oxygen saturation of $\geq 4 \%$ or waking, or both. The person who analysed the sleep recordings was blinded to group allocation throughout the trial.

The Pittsburgh quality of sleep index is a self administered questionnaire with 19 items to determine sleep quality, latency, duration, and disturbance within the past four weeks. ${ }^{14}$ The global score ranges from 0 to 21 , with higher values representing worse quality of sleep. A score of $\geq 5$ represents impaired sleep quality. We used a validated German version. ${ }^{15}$

The partners (when present) rated their sleep disturbance by the participants' snoring during the previous seven nights on a visual analogue scale from 0 to 10 . The visual analogue scale was similar to a Borg scale and had verbal descriptors for 0 (not disturbed at all) to 5 (severely disturbed), 7 (very severely disturbed), 9 (very, very severely disturbed), and 10 (extremely disturbed). The partners completed the scale independently from the participants and sent it back to the study centre.

Finally, we used the German SF-36 to assess generic health related quality of life. ${ }^{16}$

\section{Analysis}

We analysed all data on an intention to treat basis. For the primary analysis we compared change scores (differences between baseline and follow-up) between groups using two sample $t$ tests. We also performed an analysis of covariance with the primary and secondary continuous end points at four months after randomisation as the dependent variables and their baseline values, markers of severity of disease (apnoeahypopnoea index and Epworth score), weight change, and group allocation as independent variables.

We selected the Epworth scale as our primary outcome but also considered the three other sleep related outcomes (apnoeahypopnoea index, Pittsburgh quality of sleep index, and partner rating). To provide an overall estimate of the effects of didgeridoo playing on the four outcome measures we used a summary measure described by Schouten. ${ }^{17}$ Briefly, for each patient and outcome we calculated a z score (difference of individual change minus overall mean change score/overall SD of change score) and then a summary score as the average of the four $\mathrm{z}$ scores. We compared these summary scores between the groups using a two sample $t$ test.

For all analyses, we present 95\% confidence intervals and considered $\mathrm{P} \leq 0.05$ as significant. All statistical analyses were performed with SPSS (12.0.1, Chicago, Ill).

\section{Results}

Figure 2 shows the study flow from screening of potential participants to the final assessment. We included 25 patients from August 2004 to April 2005, all of whom completed the trial. Table 1 shows the participants' characteristics and the baseline values of the outcomes measures. Most patients were men, aged about 50, and had an average apnoea-hypopnoea index of 21 and excessive daytime sleepiness (mean Epworth scores 11.8 in the didgeridoo group and 11.1 in the control group). The Pittsburgh quality of sleep index indicated impaired sleep quality (5.2 and 5.8) and the partners of the study participants on average had severely disturbed sleep (5.6 and 5.5). The SF-36 scores were in the range of the normal population with exception of the mental component and vitality scores, which were lower 
On the case

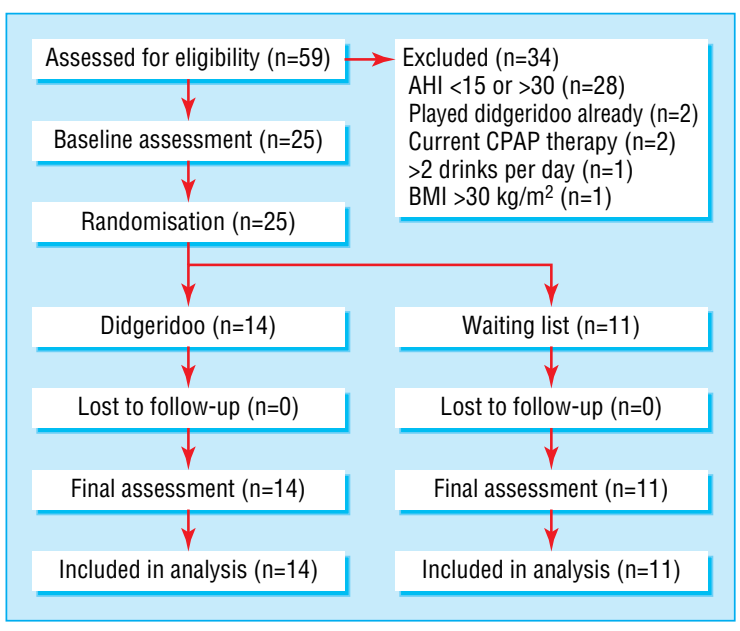

Fig 2 Flow of participants through study

(reference scores of 50 for mental component and 63.3 for vitality).

On average, participants in the didgeridoo group practised on 5.9 days a week (SD 0.86, range 4.6-6.9) for 25.3 minutes (3.4). There were no adverse or unexpected events in either group. Table 2 shows the effects of didgeridoo playing on the four sleep related outcomes. The primary outcome (daytime sleepiness as measured by the Epworth scale) improved significantly in the didgeridoo group compared with the control group (difference -3.0 units, $95 \%$ confidence interval -5.7 to $-0.3, \mathrm{P}=0.03$ ). Figure 3 shows the individual responses in daytime sleepiness in the two groups.

The quality of sleep did not differ significantly between groups (difference -0.7 units, -2.1 to $0.6, \mathrm{P}=0.27$ ), but the

Table 1 Characteristics of participants according to allocation to intervention (didgeridoo) or control. Numbers are means (SD) except for absolute values

\begin{tabular}{|c|c|c|}
\hline & $\begin{array}{l}\text { Didgeridoo group } \\
\quad(\mathrm{n}=14)\end{array}$ & Control group $(n=11)$ \\
\hline Age (years) & $49.9(6.7)$ & $47.0(8.9)$ \\
\hline Men & 12 & 9 \\
\hline Years of snoring & $8.7(6.0)$ & $8.9(3.5)$ \\
\hline Body mass index & $25.8(4.0)$ & $25.9(2.4)$ \\
\hline Systolic blood pressure & $133.7(14.0)$ & $133.3(14.0)$ \\
\hline Diastolic blood pressure & $80.9(7.1)$ & $77.3(8.4)$ \\
\hline Used any medication & 3 & 1 \\
\hline Played wind instrument & 0 & 2 \\
\hline Drinks/week & $2.2(3.1)$ & $2.2(1.8)$ \\
\hline \multicolumn{3}{|l|}{ Reason for study participation: } \\
\hline Snoring & 14 & 10 \\
\hline Intolerance to CPAP therapy & 0 & 1 \\
\hline Apnoea-hypopnoea index & $22.3(5.0)$ & $19.9(4.7)$ \\
\hline Epworth scale & $11.8(3.5)$ & $11.1(6.4)$ \\
\hline Pittsburgh quality of sleep index & $5.2(1.7)$ & $5.8(2.8)$ \\
\hline Partner's rating of sleep disturbance & $5.6(2.4)^{\star}$ & $5.5(2.3)$ \\
\hline \multicolumn{3}{|l|}{ SF-36: } \\
\hline Physical component score & $52.7(7.4)$ & $52.7(7.0)$ \\
\hline Mental component score & $41.1(12.1)$ & $44.8(8.6)$ \\
\hline Physical functioning & $88.9(11.3)$ & $92.5(8.9)$ \\
\hline Role physical & $76.2(25.1)$ & $82.5(20.6)$ \\
\hline Bodily pain & $79.2(22.0)$ & $80.9(29.1)$ \\
\hline General health & $70.4(17.1)$ & $69.9(16.0)$ \\
\hline Vitality & $48.6(15.2)$ & $53.0(11.1)$ \\
\hline Social functioning & $66.4(20.6)$ & $69.1(14.7)$ \\
\hline Role emotional & $72.2(27.9)$ & $83.5(17.4)$ \\
\hline Mental health & $66.9(19.5)$ & $68.4(15.9)$ \\
\hline
\end{tabular}

${ }^{*}$ One participant in the didgeridoo group did not have a partner.
Table 2 Effects of intervention on sleep related outcomes

\begin{tabular}{|c|c|c|c|c|}
\hline Outcome & $\begin{array}{l}\text { Didgeridoo } \\
\text { group }\end{array}$ & $\begin{array}{l}\text { Control } \\
\text { group }\end{array}$ & $\begin{array}{l}\text { Raw difference }{ }^{\star}(95 \% \\
\text { Cl) }\end{array}$ & $\begin{array}{l}\text { Adjusted difference } † \\
(95 \% \mathrm{Cl})\end{array}$ \\
\hline \multicolumn{5}{|l|}{ Epworth scale } \\
\hline At 4 months & $7.4(2.3)$ & $9.6(6.0)$ & & \\
\hline $\begin{array}{l}\begin{array}{c}\text { Change from } \\
\text { baseline }\end{array} \\
\text {. }\end{array}$ & $\begin{array}{l}-4.4 \\
(3.7)\end{array}$ & $\begin{array}{l}-1.4 \\
(2.6)\end{array}$ & 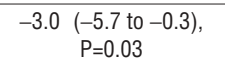 & $\begin{array}{c}-2.8(-5.4 \text { to }-0.2) \\
P=0.04\end{array}$ \\
\hline \multicolumn{5}{|c|}{ Pittsburgh quality of sleep index } \\
\hline At 4 months & $4.3(2.1)$ & $5.6(2.7)$ & & \\
\hline $\begin{array}{l}\text { Change from } \\
\text { baseline }\end{array}$ & $\begin{array}{l}-0.9 \\
(1.6)\end{array}$ & $\begin{array}{l}-0.2 \\
(1.7)\end{array}$ & $\begin{array}{c}-0.7 \begin{array}{l}(-2.1 \text { to } 0.6), \\
P=0.27\end{array}\end{array}$ & $\begin{array}{cl}-0.8 & (-2.3 \text { to } 0.8) \\
& P=0.30\end{array}$ \\
\hline \multicolumn{5}{|c|}{ Partner rating of sleep disturbance } \\
\hline At 4 months & $2.3(1.4)$ & $4.8(2.2)$ & & \\
\hline $\begin{array}{c}\text { Change from } \\
\text { baseline }\end{array}$ & $\begin{array}{l}-3.4 \\
(2.4)\end{array}$ & $\begin{array}{l}-0.6 \\
(1.9)\end{array}$ & 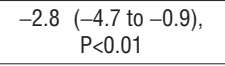 & 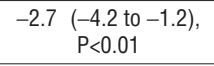 \\
\hline \multicolumn{5}{|c|}{ Apnoea-hypopnoea index } \\
\hline At 4 months & $\begin{array}{l}11.6 \\
(8.1)\end{array}$ & $\begin{array}{l}15.4 \\
(9.8)\end{array}$ & & \\
\hline $\begin{array}{l}\text { Change from } \\
\text { baseline }\end{array}$ & $\begin{array}{r}-10.7 \\
(7.7)\end{array}$ & $\begin{array}{l}-4.5 \\
(6.9)\end{array}$ & $\begin{array}{c}-6.2 \begin{array}{c}(-12.3 \text { to }-0.1) \\
P=0.05\end{array}\end{array}$ & $\begin{array}{c}-6.6(-13.3 \text { to }-0.1), \\
P=0.05\end{array}$ \\
\hline
\end{tabular}

*Two sample $t$ tests.

$\dagger$ Analysis of covariance with adjustment for severity of disease (apnoea-hypopnoea index and Epworth scale) and weight change during study period.

partners of those in the didgeridoo group reported less sleep disturbance (difference -2.8 units, -4.7 to $-0.9, \mathrm{P}<0.01$ ). We also observed a significant effect of didgeridoo playing on apnoea-hypopnoea (difference for apnoea-hypopnoea index $-6.2,-12.3$ to $-0.1, \mathrm{P}=0.05)$. Didgeridoo playing did not have a significant effect on any domain of the SF-36. Adjustment for severity of the condition and weight change during the study did not alter the results substantially for any outcome.

Figure 4 shows the combined analysis of the four sleep related outcomes. The summary $\mathrm{z}$ scores differed by -0.78 $(-1.27$ to $-0.28, \mathrm{P}<0.01)$, favouring the didgeridoo over the control group.

\section{Discussion}

In this randomised controlled trial we found that four months of training of the upper airways by didgeridoo playing reduces daytime sleepiness in people with snoring and obstructive sleep apnoea syndrome. The reduction of the apnoea-hypopnoea index by didgeridoo playing indicated that the collapsibility of the upper airways decreased. In addition, the partners of participants in the didgeridoo group were much less disturbed in their sleep.

Earlier studies about the effects of electrical neurostimulation or training of the respiratory muscles showed no improvement

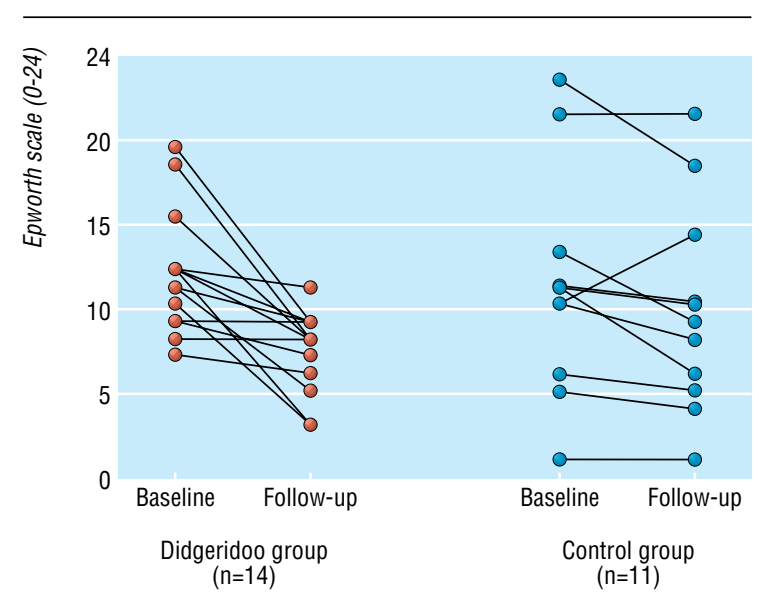

Fig 3 Individual responses in daytime sleepiness, showing direction of change 
in daytime sleepiness ${ }^{11}$ or the apnoea-hypopnoea index ${ }^{18}$ or were limited by the lack of a control group..$^{10}$ Our results are the first to show that training the upper airways significantly improves sleep related outcomes. The larger effects we observed may be due to the longer duration of our intervention and the training of the whole vocal tract instead of only single muscles.

\section{Comparison with continuous positive airway pressure therapy}

A meta-analysis of trials evaluating continuous positive airway pressure therapy in patients with moderate to severe obstructive sleep apnoea syndrome showed an average effect of -3.9 units on the Epworth scale. ${ }^{4}$ The minimum important difference on this scale for severely affected patients is around 4 units. ${ }^{19}$ In our trial, the mean change score in the didgeridoo group was -4.4 units and the difference between the intervention and control group was -3.0 units. Thus the effect of didgeridoo playing seems to be slightly smaller than with CPAP therapy. However, we expected smaller effects because our patients were only moderately affected so that results are likely to be less pronounced.

One of the challenges in the treatment of sleep disorders is poor compliance. ${ }^{120}$ Thus new treatments not only need to be effective but also be ones that people are motivated enough to use. Didgeridoo playing seems to meet these requirements. Participants were highly motivated during the trial and practised, on average, on almost six days a week, which was even more than the protocol asked for.

\section{Strengths and limitations of trial}

Strengths of our trial include the long duration of the training so that effects could develop. Also, we blinded outcomes assessors when possible (sleep studies) and controlled for confounding by restricting the study sample to non-obese patients with little alcohol and drug consumption. A limitation is that those in the control group were simply put on a waiting list because a sham intervention for didgeridoo playing would be difficult. A control intervention such as playing a recorder would have been an option, but we would not be able to exclude effects on the upper airways and compliance might be poor. Another limitation is that the sample size was small. We conducted a proof of concept study and larger trials with more diverse study populations are needed to provide more precise estimates of the treatment effect of upper airway training.

In conclusion, didgeridoo playing improved daytime sleepiness in patients with moderate snoring and obstructive sleep apnoea and reduced sleep disturbance in their partners. Larger trials are needed to confirm our preliminary findings, but our results may give hope to the many people with moderate obstructive sleep apnoea syndrome and snoring, as well as to their partners.

\section{What is already known on this topic}

Snoring and obstructive sleep apnoea syndrome are highly prevalent sleep disorders associated with substantial morbidity and mortality and rising costs

Continuous positive airways pressure therapy can reduce daytime sleepiness, but compliance with this treatment is often poor

Training or electrostimulation of the muscles of the upper airway might reduce collapsibility of the upper airways during sleep

\section{What this study adds}

Regular playing of a didgeridoo reduces daytime sleepiness and snoring in people with moderate obstructive sleep apnoea syndrome and also improves the sleep quality of partners

Severity of disease, expressed by the apnoea-hypopnoea index, is also substantially reduced after four months of didgeridoo playing

Contributors: MAP, AS, and OB designed and organised the study. AS assigned the intervention. CLC, OB, MH, and AZ collected the data. MAP supervised data collection, analysed data, and wrote the first draft. AS, CLC, $\mathrm{AZ}, \mathrm{MH}$, and $\mathrm{OB}$ critically reviewed the manuscript, and MAP and $\mathrm{OB}$ prepared the final version. $\mathrm{OB}$ is guarantor.

Funding: Zurich Lung Association, Zuercher Hoehenklinik Wald.

Competing interests: AS is a professional didgeridoo instructor and teaches t'ai chi and qi gong.

Ethical approval: Ethics committee of the University Hospital of Zurich.

1 Caples SM, Gami AS, Somers VK. Obstructive sleep apnea. Ann Intern Med 2005;142:187-97.

2 Duran J, Esnaola S, Rubio R, Iztueta A. Obstructive sleep apnea-hypopnea and related clinical features in a population-based sample of subjects aged 30 to $70 \mathrm{yr}$. Am J Respir Crit Care Med 2001;163:685-9.

3 Young T, Palta M, Dempsey J, Skatrud J, Weber S, Badr S. The occurrence of sleep-disordered breathing among middle-aged adults. N Engl J Med 1993;328:1230-5.

4 White J, Cates C, Wright J. Continuous positive airways pressure for obstructive sleep apnoea. Cochrane Database Syst Rev 2002;(2):CD001106.

5 Marin JM, Carrizo SJ, Vicente E, Agusti AG. Long-term cardiovascular outcomes in men with obstructive sleep apnoea-hypopnoea with or without treatment with continuous positive airway pressure: an observational study. Lancet 2005;365:1046-53.

6 Lewis KE, Seale L, Bartle IE, Watkins AJ, Ebden P. Early predictors of CPAP use for the treatment of obstructive sleep apnea. Sleep 2004;27:134-8.

7 Pepin JL, Krieger J, Rodenstein D, Cornette A, Sforza E, Delguste P, et al. Effective compliance during the first 3 months of continuous positive airway pressure. A European prospective study of 121 patients. Am J Respir Crit Care Med 1999;160:11249.

8 Mann EA, Burnett T, Cornell S, Ludlow CL. The effect of neuromuscular stimulation of the genioglossus on the hypopharyngeal airway. Laryngoscope 2002;112:351-6.

9 Randerath WJ, Galetke W, Domanski U, Weitkunat R, Ruhle KH. Tongue-muscle training by intraoral electrical neurostimulation in patients with obstructive sleep apnea. Sleep 2004;27:254-9.

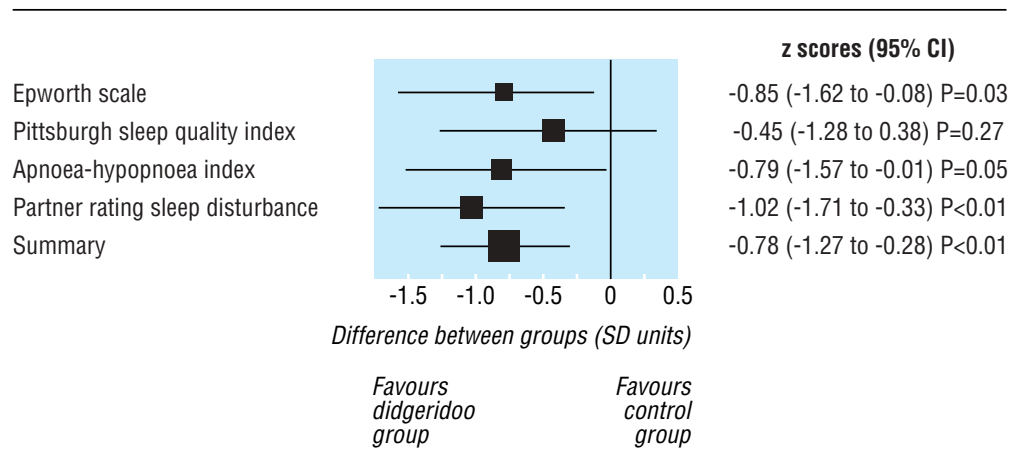

Fig 4 Effects of didgeridoo playing on measure of sleep related outcomes 
10 Verse T, Schwalb J, Hormann K, Stuck BA, Maurer JT. [Submental transcutaneous electrical stimulation for obstructive sleep apnea]. HNO 2003;51:966-70.

11 Tarnopolsky A, Fletcher N, Hollenberg L, Lange B, Smith J, Wolfe J. Acoustics: the vocal tract and the sound of a didgeridoo. Nature 2005;436:39.

12 Bloch KE, Schoch OD, Zhang JN, Russi EW. German version of the Epworth sleepiness scale. Respiration 1999;66:440-7.

13 German Society for Sleep Research and Medicine. Guidelines for diagnosis and therapy. In: Schulz H, ed. Kompendium Schlafmedizin für Ausbildung, Klinik und Praxis. Landsberg: Ecomed, 2005.

14 Buysse DJ, Reynolds CF, III, Monk TH, Berman SR, Kupfer DJ. The Pittsburgh sleep quality index: a new instrument for psychiatric practice and research. Psychiatry Res 1989:28:193-213.

15 Backhaus J, Niemann T, Hohagen F, Riemann D, Junghanns K. Test-retest reliablity of the Pittsburgh sleep quality index (=PSQI) in patients with primary insomnia. World $J$ Biol Psychiatry 2001:374S.

16 Bullinger M. German translation and psychometric testing of the SF-36 health survey: preliminary results from the IQOLA Project. International quality of life assessment. Soc Sci Med 1995;41:1359-66.

17 Schouten HJ. Combined evidence from multiple outcomes in a clinical trial.J Clin Epidemiol 2000;53:1137-44

18 Furrer-Boschung E, Bauer W, Boutellier U. Therapy of snoring by respiratory muscle training [doctoral thesis]. Zurich: University of Zurich, 1997.

19 Kingshott RN, Vennelle M, Coleman EL, Engleman HM, Mackay TW, Douglas NJ. Randomized, double-blind, placebo-controlled crossover trial of modafinil in the treatment of residual excessive daytime sleepiness in the sleep apnea/hypopnea syndrome. Am J Respir Crit Care Med 2001;163:918-23.

20 Engleman HM, Kingshott RN, Wraith PK, Mackay TW, Deary IJ, Douglas NJ. Randomized placebo-controlled crossover trial of continuous positive airway pressure for mild sleep apnea/hypopnea syndrome. Am J Respir Crit Care Med 1999;159:461-7.

(Accepted 24 November 2005)

doi $10.1136 /$ bmj. 38705.470590 .55

Horten Centre, University of Zurich, 8091 Zurich, Switzerland Milo A Puhan research fellow

Asate Alex Suarez, 9630 Wattwil, Switzerland

Alex Suarez didgeridoo instructor

Zuercher Hoehenklinik Wald, CH-8639 Faltigberg-Wald, Switzerland

Christian Lo Cascio resident in internal medicine

Alfred Zahn sleep laboratory technician

Otto Braendli specialist in respiratory and sleep medicine

Lungenpraxis Morgental, Zurich, Switzerland

Markus Heitz specialist in respiratory and sleep medicine

Correspondence to: O Braendli otto.braendli@zhw.ch 